\title{
Respiratory intensive care units in Italy: a national census and prospective cohort study
}

\author{
M Confalonieri, M Gorini, N Ambrosino, C Mollica, A Corrado, on behalf of the \\ Scientific Group on Respiratory Intensive Care of the Italian Association of Hospital \\ Pneumologists (AIPO) *
}

Unità Operativa di Pneumologia, Ospedali Riuniti di Trieste, Trieste, Italy M Confalonieri

Unità di Terapia Intensiva Respiratoria, Ospedale Careggi di Firenze, Firenze, Italy M Gorini

A Corrado

Divisione di Pneumologia, IRCCS Fondazione "S. Maugeri” di Gussago, Gussago, Italy N Ambrosino

Unità di Terapia Intensiva Respiratoria, STIRS, Ospedale "Forlanini" di Roma, Rome, Italy C Mollica

${ }^{\star}$ Members of the Scientific Group on Respiratory Intensive Care of the AIPO are listed at the end of the paper.

Correspondence to: Dr M Confalonieri, U.O. Pneumologia, Azienda Ospedaliera di Trieste, Via Bonomia 265, 34100 Trieste, Italy

mconfalonieri@qubisoft.it

Received 11 July 2000 Returned to authors 23 October 2000 Revised version received 18 December 2000 Accepted for publication 30 January 2001

\begin{abstract}
Background-In Italy, respiratory intensive care units (RICUs) provide an intermediate level of care between the intensive care unit (ICU) and the general ward for patients with single organ respiratory failure. Because of the lack of official epidemiological data in these units, a two phase study was performed with the aim of describing the work profile in Italian RICUs.

Methods-A national survey of RICUs was conducted from January to March 1997 using a questionnaire which comprised over 30 items regarding location, models of service provision, staff, and equipment. The following criteria were necessary for inclusion of a unit in the survey: (1) a nurse to patient ratio ranging from $1: 2.5$ to $1: 4$ per shift; (2) availability of adequate continuous non-invasive monitoring; (3) expertise for non-invasive ventilation (NIV) and for intubation in case of NIV failure; (4) physician availability 24 hours a day. Between November 1997 and January 1998 a 3 month prospective cohort study was performed to survey the patient population admitted to the RICUs.
\end{abstract}

Results-Twenty six RICUs were included in the study: four were located in rehabilitation centres and 22 in general hospitals. In most, the reported nurse to patient ratio ranged from $1: 2$ to $1: 3$, with $36 \%$ of units reporting a ratio of $1: 4$ per shift. During the study period 756 consecutive patients of mean (SD) age 68 (12) years were admitted to the 26 RICUs. The highest proportion ( $47 \%$ ) were admitted from emergency departments, $19 \%$ from other medical wards, $18 \%$ were transferred from the ICU, $13 \%$ from specialist respiratory wards, and $2 \%$ were transferred following surgery. All but 32 had respiratory failure on admission. The reasons for admission to the RICU were: monitoring for expected clinical instability $(n=221)$, mechanical ventilation $(n=473)$, and weaning $(n=59)$; 586 patients needed mechanical ventilation during their stay in the RICU, 425 were treated with noninvasive techniques as a first line of treatment (374 by non-invasive positive pressure, 51 by iron lung), and 161 underwent invasive mechanical ventilation (63 intubated, 98 tracheostomies). All but 48 patients had chronic respiratory disease, mainly chronic obstructive pulmonary disease (COPD; $\mathbf{n}=451$ ). More than $70 \%$ of patients $(n=228)$ had comorbidity, mainly consisting of heart disorders. The median APACHE II score was 18 (range 1-43). The predicted inpatient mortality risk rate according to the APACHE II equation was $22.1 \%$ while the actual inpatient mortality rate was $16 \%$. The mean length of stay in the RICU was 12 (11) days. The outcome in most patients $(79.2 \%)$ admitted to RICUs was favourable.

Conclusions-Italian RICUs are specialised units mainly devoted to the monitoring and treatment of acute on chronic respiratory failure by non-invasive ventilation, but also to weaning from invasive mechanical ventilation. The results of this study provide a useful insight into an increasingly important field of respiratory medicine.

(Thorax 2001;56:373-378)

Keywords: respiratory intensive care units; non-invasive ventilation; weaning; chronic obstructive pulmonary disease; respiratory failure; critical care medicine

Unlike the situation in North America, respiratory physicians in Italy and in most other European countries have not been involved in critical care medicine until recently. ${ }^{1}$ In the USA respiratory specialists have been running respiratory intensive care units (RICUs) since the $1960 \mathrm{~s}^{2}$ and, since the late $1980 \mathrm{~s}$, noninvasive respiratory care units (NRCUs) and high dependency units (HDUs). ${ }^{34}$ The effectiveness of these intermediate units, both in medical and economic terms, has already been described. ${ }^{56}$ The experiences reported suggest that it is possible to provide effective care for patients with acute on chronic respiratory failure and/or those requiring prolonged mechanical ventilation outside the general intensive care unit (ICU), and at a lower cost. In Europe respiratory care units have only been developed relatively recently, ${ }^{7}$ but there has been a rapid increase in numbers in recent years. ${ }^{8}$ European RICUs tend to serve as specialised single organ units at an intermediate level of care between the ICU and general ward, but their characteristics are not homogeneous.

There has been a growing interest in RICUs over the last 10 years in Italy and it is estimated that Italy is presently the European country with the largest number of units run by respiratory physicians. ${ }^{8}$ The number of RICUs being opened up in respiratory departments has risen dramatically since the end of the 
1980s when non-invasive mechanical ventilation and monitoring became popular. The Italian Association of Hospital Pulmonologists (AIPO) took the lead in this field by defining and establishing good practice in RICUs as "an area for the monitoring and treatment of patients with acute respiratory failure due to a primary respiratory cause and of patients with acute or chronic respiratory failure. Noninvasive monitoring techniques and noninvasive mechanical ventilation should be principally employed as first line of treatment; however, when mandatory, invasive techniques must be used." Furthermore, the AIPO statement describes an RICU as having a nurse to patient ratio of $1: 2.5-3$ with specific respiratory facilities such as the ability to perform a tracheostomy. In 1988 the Italian NHS recommended a nurse to patient ratio of $1: 4$ for intermediate intensive care units but respiratory medicine was not among the specialties included. ${ }^{10}$ Because of the lack of official national data regarding the epidemiology of RICUs, the AIPO Respiratory Intensive Care Working Group conducted a two phase study aimed at describing the profile of RICUs in Italy including the number of units, their features, and the characteristics of patients admitted. This paper presents the results of that study.

\section{Methods}

A national survey of RICUs was conducted on behalf of the AIPO from January 1997 to March 1997. Between November 1997 and January 1998 a 3 month prospective cohort study was performed to survey the patient population admitted to RICUs.

NATIONAL CENSUS OF RICUS

The names of the RICUs were collected on a regional basis from selected respiratory physicians involved in critical care medicine who contacted all the main hospitals in their region. These colleagues were chosen for their thorough knowledge of all the respiratory centres in their area. A questionnaire comprising more than 30 items was mailed to the centres identified. Three weeks were allowed for completion of the questionnaires and any point of ambiguity was clarified by a telephone survey. The total time taken for data collection was 8 weeks. In each centre the reference respiratory physician vouched for the accuracy of the collected data. To be included in the census a unit had to fulfil the following criteria:

- a nurse to patient ratio of $1: 2.5$ to $1: 4$ per shift;

- availability of adequate continuous noninvasive monitoring (minimum requirements ECG, oximetry $\left(\mathrm{SaO}_{2}\right)$, non-invasive blood pressure, and respiratory rate);

- expertise in establishing and maintaining non-invasive ventilation (NIV);

- facilities and expert personnel to establish urgent endotracheal intubation should NIV fail;

- resident medical staff available 24 hours a day.
COHORT STUDY

The RICUs identified were asked to recruit consecutive patients seen over the same 3 month period into the study. Single patient forms were distributed and completed by the physicians in charge of each RICU. Collection of data on admissions to the RICUs began on 1 November 1997 and was completed on 31 January 1998. The cases recruited made up a cohort of patients who were followed prospectively during their stay in the RICU, thus providing a description of the procedures and interventions each patient underwent and the final outcome.

The information regarding each patient comprised: demographics and anthropometrics, reason for admission, location of patient before admission, diagnostic profiles, coexisting chronic diseases, respiratory parameters on admission, patient's overall severity by APACHE II score, ${ }^{11}$ treatment given during stay in RICU, patient outcome, and duration of stay in RICU and in hospital. The patient data collected were anonymous to ensure ethical approval for the study. The Acute Physiology Score (APS), a component of the full APACHE II score, was determined from the worst physiological values during the initial 24 hours after admission to the RICU. The total APACHE II score was calculated by adding the patient's age and comorbidity score to the APS. ${ }^{11}$ The method described by Knaus et $a l^{11}$ was used to compute the predicted risk of hospital mortality for each patient.

\section{Results}

NATIONAL CENSUS OF RICUS

All the centres returned fully completed questionnaires. Of the 33 centres studied, 26 were identified which fulfilled all five inclusion criteria (four in pulmonary rehabilitation centres and 22 in general hospitals). Geographical distribution was uneven with $61.5 \%, 19 \%$, and $15 \%$ being situated in the north, centre and south of Italy, respectively. The total number of beds was 155, ranging from three to nine beds per unit. Over half of the units (64\%) reported a nurse to patient ratio ranging from $1: 2$ to $1: 3$, while $36 \%$ of units reported a ratio of $1: 4$ per shift. Over half $(65 \%)$ were located within a respiratory department so that staff could be used more flexibly when patients admitted to the RICU needed more care. There was at least one doctor on duty during the day and one on call at night. The mean medical doctor to patient ratio was $1: 9$ in $80 \%$ of RICUs. All 26 RICUs were equipped for non-invasive monitoring (at least continuous ECG tracing, blood pressure, and $\mathrm{SaO}_{2}$ ) and mechanical ventilation (at least one ICU/life support ventilator in 24 units), but only in two RICUs was it possible to perform invasive haemodynamic monitoring. Endotracheal intubation was possible in all 26 units if NIV failed, but mechanical ventilation in intubated patients with single organ failure was available only in 16 units. In the remaining units mechanical ventilation in intubated patients was performed in an adjacent ICU. 
Table 1 Characteristics of patients admitted to RICU

\begin{tabular}{|c|c|c|c|c|}
\hline & $\begin{array}{l}\text { Hypoxaemic- } \\
\text { hypercapnic } \\
\text { acute respiratory } \\
\text { failure }\end{array}$ & $\begin{array}{l}\text { Hypoxaemic- } \\
\text { normo/hypocapnic } \\
\text { acute respiratory } \\
\text { failure }\end{array}$ & Weaning & Total \\
\hline No $(\%)$ & $518(68)$ & $179(24)$ & $59(8)$ & $756(100)$ \\
\hline Age (years) & $69(10)$ & $63(17)$ & $67(10)$ & $68(12)$ \\
\hline APACHE II score & $19(6)$ & $15(7)$ & $14(4)$ & $18(6)$ \\
\hline Glasgow coma score & $13(2)$ & $14(1)$ & $14(1)$ & $13(2)$ \\
\hline $\mathrm{PaO}_{2}$ at admission ${ }^{\star}(\mathrm{kPa})$ & $5.5(1.1)$ & $6.4(1.3)$ & $10.5(3.1)$ & $5.9(1.7)$ \\
\hline $\mathrm{PaCO}_{2}$ at admission $(\mathrm{kPa})$ & $10.2(2.6)$ & $4.8(0.8)$ & $7.2(1.9)$ & $8.9(3.1)$ \\
\hline $\mathrm{pH}$ at admission & $7.30(0.08)$ & $7.41(0.07)$ & $7.39(0.07)$ & $7.34(0.09)$ \\
\hline $\begin{array}{l}\text { Respiratory rate at admission } \\
\text { (breath/min) }\end{array}$ & $27(7)$ & $27(8)$ & $23(6)$ & $26(7)$ \\
\hline
\end{tabular}

$\star \mathrm{FiO}_{2}=0.21$ but $\mathrm{FiO}_{2}>0.21$ if weaning.

Table 2 Chronic respiratory diseases of patients admitted to RICU

\begin{tabular}{lccc}
\hline Chronic respiratory diseases & No of patients & \% of total & $\begin{array}{l}\text { \% favourable } \\
\text { outcome }^{\star}\end{array}$ \\
\hline None & 48 & 6.3 & 83.3 \\
COPD & 451 & 59.6 & 78.7 \\
Asthma & 18 & 2.3 & 81.3 \\
Chest wall diseases & 38 & 5.0 & 86.8 \\
Neuromuscular diseases & 30 & 3.9 & 80.0 \\
Pulmonary fibrosis & 22 & 2.9 & 72.7 \\
TB sequelae & 36 & 4.7 & 83.8 \\
Hypoventilation obesity syndrome & 44 & 5.8 & 82.0 \\
OSAS & 12 & 1.5 & 90.0 \\
Other & 57 & 7.5 & 77.1 \\
\hline
\end{tabular}

OSAS = obstructive sleep apnoea syndrome.

$\star \%$ improved patients (discharged to home or ordinary ward).

\section{COHORT STUDY}

All RICUs which participated in the study provided data about patient admission. During the 3 month study period 756 patients ( 480 men, 276 women) of mean (SD) age 68 (12) years (30\% aged over 75 ) were admitted to the 26 RICUs. Enrollment was evenly distributed throughout the 3 months $(267,230$, and 259 patients, respectively) and ranged from 5 to 25 patients per month per RICU; 356 of the 756 patients $(47 \%)$ were transferred from an emergency department, 13\% (102 patients) from a respiratory ward, 18\% (134 patients) from a general ICU, 19\% (147 patients) from other medical wards, while $2 \%$ (17 patients) were postoperative patients. Table 1 summarises the characteristics of the patients.

On admission all but 32 of the 756 patients had acute respiratory failure as assessed by arterial blood gas analysis. The reasons for admission to the RICU were monitoring for clinical instability (29\%), need for non-invasive or mechanical ventilation (63\%), and difficulty in weaning from mechanical ventilation $(8 \%)$. A total of $451(59.6 \%)$ had chronic obstructive pulmonary disease (COPD) and only 48 patients $(6 \%)$ were not suffering from a chronic respiratory disease; $542(72 \%)$ presented with at least one comorbid condition on admission, most commonly cardiac disease $(n=228)$.

Table 3 Chronic comorbidity in the study population

\begin{tabular}{lcl}
\hline Chronic condition & $\begin{array}{l}\text { No (\%) of } \\
\text { patients }\end{array}$ & $\begin{array}{l}\text { Unfavourable } \\
\text { outcome (\%)* }\end{array}$ \\
\hline None & $214(28.3)$ & 14.9 \\
Cardiac disease & $228(30.1)$ & 22.3 \\
Renal disease & $32(4.2)$ & 31.2 \\
Cirrhosis & $20(2.6)$ & 20.0 \\
Malignancy & $56(7.4)$ & 27.5 \\
Diabetes & $82(10.8)$ & 26.6 \\
Rheumatic disease & $6(0.7)$ & 20 \\
Other & $128(16.9)$ & 16.4 \\
\hline
\end{tabular}

^Dead or transferred to ICU.

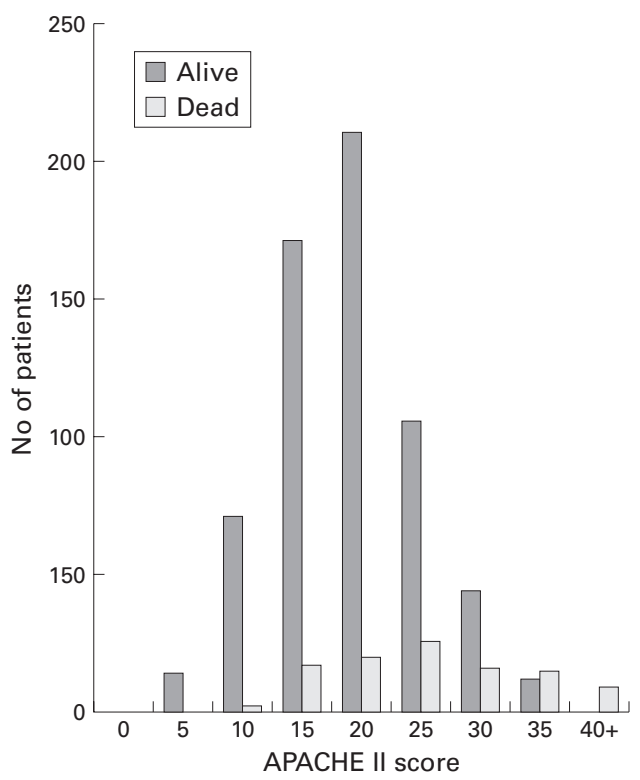

Figure 1 APACHE II score distribution.

Tables 2 and 3 show the spectrum of respiratory chronic diseases and nonrespiratory comorbid conditions in the patients.

The median APACHE II score was 18 (range 1-43). Figure 1 shows the distribution of APACHE II scores according to survival or death in hospital. Invasive monitoring procedures (insertion of a central venous line and pulmonary artery catheterisation) were performed in $21.4 \%$ and $6.3 \%$ of cases, respectively; supplemental enteral and/or parenteral nutrition was provided in $15.2 \%$ of patients. There were 586 patients who needed mechanical ventilation during their stay in the RICU; 425 were treated with non-invasive techniques as first line treatment (374 non-invasive positive pressure, 51 iron lung), while the remaining 161 patients underwent invasive mechanical ventilation (63 intubated, 98 tracheostomies). In 127 patients NIV was the only weaning method used. Recent tracheostomy was closed in the RICU in 29 out of 64 patients.

Table 4 Outcome of the patients admitted to RICU

\begin{tabular}{ll}
\hline Outcome & No (\%) of patients \\
\hline Discharged & $352(46.5)$ \\
Transferred to ward & $247(32.6)$ \\
Transferred to ICU & $42(5.5)$ \\
Dead in HDU & $96(12.6)$ \\
Mortality 1 month after discharge & $25 / 444(5.6)$ \\
\hline
\end{tabular}

HDU $=$ high dependency unit.

Table 5 Complications in RICU

\begin{tabular}{lc}
\hline & No (\%) patients \\
\hline Heart failure & $50(6.6)$ \\
Severe arrhythmias & $50(6.6)$ \\
Acute renal failure & $27(3.5)$ \\
Pneumothorax & $3(0.3)$ \\
Coma & $37(4.8)$ \\
Pulmonary embolism & $2(0.2)$ \\
Gastrointestinal haemorrhage & $17(2.2)$ \\
Shock & $21(2.7)$ \\
Nosocomial infection & $16(2.1)$ \\
Other & $45(7.8)$ \\
No complications & $473(62.5)$ \\
\hline
\end{tabular}




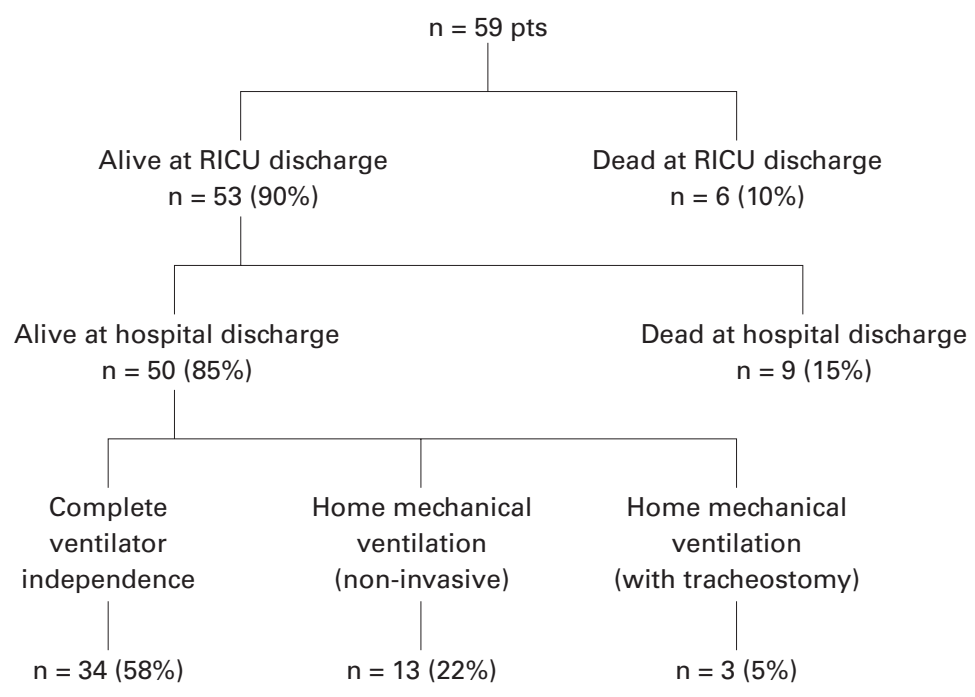

Figure 2 Admission to RICU for weaning from mechanical ventilation.

The outcome was favourable in most of the cases who survived $(79.2 \%$; table 4$)$. The predicted in-hospital mortality risk rate according to the APACHE II equation ${ }^{11}$ was $22.1 \%$ in our study population. During the RICU stay $30 \%$ of patients suffered from major complications (table 5). Figure 2 shows the outcome for the subgroup of patients admitted to the RICU for weaning from mechanical ventilation. The mean length of stay in the RICU was 12 (11) days, with more than $35 \%$ of patients being discharged within one week and $18 \%$ dying in hospital. The difference in length of stay was related to the reason for admission: 10 days for patients admitted for monitoring purposes, 12 days for those who needed mechanical ventilation, and 21.3 days for patients with difficulty in weaning. Of the patients who survived, $58.8 \%$ were discharged home directly while $41 \%$ were transferred to the general ward before discharge.

\section{Discussion}

Although European respiratory physicians are taking an increasing interest in pulmonary critical care, there are very few data about the changing role of respiratory medicine in Europe. In particular, the rising number of RICUs in some European countries such as Italy testifies to the increasing importance of intensive care in European respiratory medicine. ${ }^{8}$ The main objective of this study was to establish the prevalence of RICUs in Italy and to provide a detailed description of the type of patient generally admitted.

The RICU is typically created within specialised respiratory departments and is run by respiratory physicians, sometimes in collaboration with specialised intensive care practitioners. ${ }^{9}$ In France respiratory units are organised into three different levels of care, ${ }^{12}$ which vary from intermediate non-invasive monitoring units providing only non-invasive monitoring ${ }^{13}$ to specialised units which are very similar to the medical ICU. ${ }^{14}$ Unlike France, however, in Italy there is no formal classification of levels of care. It should be pointed out that the AIPO statement recommended a nurse to patient ratio higher than the one considered sufficient by the Italian law for an intermediate intensive care unit (1:4). It is therefore possible to distinguish at least two different types of units with different levels of care, depending on the nurse to patient ratio. In AIPO terms only 16 of the units studied can be defined as RICUs while the 10 units with a nurse to patient ratio of $1: 4$ should be considered as NRCUs or noninvasive respiratory units. ${ }^{3}{ }^{8}$ In these NRCUs it is possible to manage airways with endotracheal intubation but, if invasive mechanical ventilation is required, the intubated patient is transferred to an adjacent general intensive care unit. However, all Italian units prefer to provide patients with non-invasive mechanical ventilation and monitoring.

The number of units has grown in the last 10 years as a result of increasing interest by Italian respiratory physicians in non-invasive mechanical ventilation and intensive care, and the availability of non-invasive monitoring devices. ${ }^{15}$ Given that general ICUs are very expensive resources, a graded care option ranging from the general ward to the ICU could provide a rational answer to the care requirements of many patients, especially for those with an acute exacerbation of a chronic respiratory disease. ${ }^{5}$ In fact, Italian RICUs may function not only as a buffer between the ICU and the conventional ward, but also as a place for treating certain forms of acute respiratory failure, particularly acute or chronic respiratory failure resulting from an exacerbation of COPD. Patients with acute on chronic respiratory failure who need mechanical ventilation may undergo a prolonged stay in the ICU, not only for the disease underlying the respiratory failure but also for ICU related complications. ${ }^{16-18}$ Furthermore, the presence of an RICU in a general hospital allows patients to be admitted for monitoring purposes, thus increasing bed availability in the traditional ICU where some patients do not actually need active intensive care. At the same time, the availability of RICU beds makes it possible to avoid providing a lower level of care on a general ward to patients judged unsuitable for ICU admission.

A prospective study performed at Nottingham City Hospital showed an improved outcome of patients admitted to a thoracic HDU compared with patients who fulfilled the criteria for HDU admission but who were managed in the general ward. ${ }^{19}$ Although we did not perform a cost analysis, it seems reasonable to assume that some of the patients admitted to the RICU avoided admission to an ICU, and this clearly has potential implications for saving costs. Byrick et $a l^{6}$ found that closure of an intermediate ICU in a general hospital increased non-emergency admissions to the ICU from $18 \%$ to $27 \%$, and that the severity of illness score in the patients admitted to the ICU decreased, showing that an increased number of less critical patients were treated at a higher cost. Elpern et a $\bar{t}$ reported a pro capita decrease in daily costs of almost $\$ 2000$ associated with the transfer of ventilated patients from an ICU to an RICU. 
The present study shows that another important function of Italian RICUs, particularly those situated in rehabilitation centres, is the admission of patients who failed to be weaned off mechanical ventilation in general ICUs, thus contributing to further ICU bed availability. Experience with specialised units for long term ventilated patients in the USA has shown that these units are an effective and cost saving alternative to the ICU for selected patients. $^{2021}$ Patients admitted to Italian RICUs with a primary indication of weaning from mechanical ventilation achieved rates of complete ventilator independence similar to those reported in larger North American series. ${ }^{20-23}$ However, a comparison of the outcome of patients admitted to the RICU directly from the emergency room or the general ward with acute respiratory failure with that of other cohorts of patients is difficult as there are few published data.

Most reports on the outcome of patients with acute respiratory failure refer to general HDUs or ICUs, but patients in Italian RICUs are not entirely comparable with those in a general HDU or ICU. Nevertheless, the decision to intubate and invasively ventilate patients with COPD might influence certain outcomes such as the severity of illness score. ${ }^{24} 25$ A UK survey on the outcome of patients with COPD admitted to the ICU for invasive mechanical ventilation (mean APACHE II score 16.5) showed a very poor inpatient survival rate (49\%) and the quality of life of most of the patients deteriorated after discharge from hospital. ${ }^{26}$ Another recent UK study reported a better outcome for patients with COPD treated with NIV in a ward setting, but only among the less severe cases. ${ }^{27}$ Sun et $a l^{28}$ reported a mortality rate in 733 patients with acute respiratory failure associated with COPD $(55 \%$ of whom underwent mechanical ventilation) of $32.7 \%$ among inpatients and $18.6 \%$ in those in the ICU. Portier et $a l^{29}$ reported a short term survival rate of $86 \%$ in a patient population affected by acute or chronic respiratory failure ( $45 \%$ COPD) followed up 1 month after discharge from the ICU, but only $52 \%$ required mechanical ventilation.

On the whole, the outcome of patients treated in Italian RICUs can be considered very satisfactory. Survival at discharge from hospital was nearly $85 \%$ compared with a mean predicted mortality rate of about $20 \%$ according to the APACHE II score on admission to the RICU. We postulate that routine use of non-invasive mechanical ventilation and monitoring in Italian RICUs might have had a favourable influence on the outcome of these patients. In conclusion, the data presented here provide some interesting insights into a rapidly expanding field of respiratory medicine.

Appendix 1: Census questionnaire items

STRUCTURAL DESCRIPTION OF RICU

- address of the RICU

- name of the RICU responsible

- type of hospital (general hospital, rehabilitation centre, university hospital)

- regional acknowledgement
- institution by the local hospital authority

- location of RICU (inside respiratory department, autonomous)

- type and number of beds

- closeness to an ICU

- criteria for admission to RICU

- average number of patients admitted in 1 year.

FACILITIES AVAILABLE IN THE RICU

- monitoring systems (invasive, non-invasive)

- ventilators (ICU ventilators, home positive pressure ventilators, iron lung)

- facilities for monitoring respiratory mechanics

- facilities for urgent endotracheal intubation readily available with ready access to invasive ventilation (which often means transfer to an ICU) should NIV fail

- availability of invasive haemodynamic monitoring

- expertise in establishing and maintaining noninvasive ventilation.

STAFF INFORMATION

- number of nurses for shift

- medical staff (number, type of specialisation, presence on duty: present 24 hours a day or present during the day and on call by night)

- respiratory therapist staff

- presence of a medical coordinator.

${ }^{\star}$ Members of the Scientific Group on Respiratory Intensive Care of the Italian Association of Hospital Pneumologists (AIPO): A Rossi (Bergamo), C Del Bufalo (Bologna), A Cavalli (Bologna), A Ferretti (Bologna), F Tomazzoni (Bolzano), G Begher (Bolzano), A Murgia (Cagliari), E Guffanti (Casatenovo), M Colombo (Casatenovo), L Pesce (Cittadella), A Marcolongo (Cittadella), R Della Porta (Crema), L Gandola (Crema), A Potena (Ferrara), S Putinati (Ferrara), M Piattella (Ferrara), U Vincenzi (Foggia), E Clini (Gussago), M Vitacca Gussago), C Sturani (Mantova), V Galavotti (Mantova), M Moretti (Modena), C F Marchioni (Modena), E Zanotti (Montescano), S Nava (Montescano), A Vianello (Padova), A LoCoco (Palermo), N Marchese (Palermo), R Melej (Parma), G F Consigli (Parma), A Eslami (Perugia), T Todisco (Perugia), G Gadaleta (Pesaro), A Rossi (Pesaro), G Reale (Roma), A Petraglia (Salerno), D Ansalone (Salerno), V Rastelli (Sondalo), D raglia (Salerno), D Ansalone (Salerno), V Rastelli (Sondalo), D Sella (Trento), G Santelli (Treviso), M Nizzetto (Treviso), S DeToni (Vicenza).

1 Roussos C, Rossi A. Pulmonologists and the respiratory intensive care. Eur Respir F 1996;9:183.

2 Petty TL, Lakshminaryan S, Sahn SA, et al. Intensive respiratory care unit. Review of ten's years experience. $7 A M A$ 1975;233:34-7.

3 Bone RC, Balk RA. Non-invasive respiratory care unit. Chest 1988;93:390-4.

4 Gracey DR, Viggiano RW, Naessens JM, et al. Outcomes of patients admitted to a chronic ventilator-dependent unit in
an acute care hospital. Mayo Clin Proc 1992;67:131-6.

5 Elpern EH, Silver MR, Rosen RL, et al. The non-invasive Elpern EH, Silver MR, Rosen RL, et al. The non-invasive
respiratory care unit. Pattern of use and financial respiratory care unit. Pattern

implications. Chest 1991;99:205-8.
6 Byrick RJ, Mazer CD, Caskenette GM. Closure of an intermediate care unit: impact on critical care utilization. Chest 1993;104:876-81.

7 French Multicentric Group of ICU Research and the INSERM Unit 169 of Statistical and Epidemiological Studies. Description of various types of intensive and intermediate care units in France. Intensive Care Med 1989;15: $260-5$.

8 Nava S, Confalonieri M, Rampulla C. Intermediate respiratory intensive care units in Europe: a European perspective. Thorax 1998;53:798-802.

9 Corrado A, Ambrosino N, Rossi A, et al. Unità di terapia intensiva respiratoria. Rassegna Patologia Apparato Respiratorio 1994;9:115-23.

10 Corrado A, Confalonieri M. Respiratory high dependency care unit in Italy. Monaldi Arch Chest Dis 1999;54: care unit

11 Knaus WA, Draper EA, Wagner DP, et al. APACHE II: a severity of disease classification system. Crit Care Med 1985;13:818-29.

2 Mayaud C, Derenne JP. Champ et perspectives de la réanimation respiratoire en pneumologie. Rev Mal Respir 1999; 16:310-2

13 Auriant I, Vinatier I, Thaler F, et al. Simplified Acute Physiology Score II for measuring severity of illness in intermediate care units. Crit Care Med 1998;26:1368-71.

14 Muir JF, Mayaud C, Derenne JP. Respiratory high dependency care units (RHDCU) in France. Monaldi Arch Chest Dis 1999;54:452-5.

15 Vitacca M, Clini E, Scalvini S, et al. Cardiopulmonary intermediate intensive care unit: time course of two years activity. Monaldi Arch Chest Dis 1993;48:296-300. 
16 Fagon JY, Chastre J, Hance AJ, et al. Nosocomial pneumonia in ventilated patients: a cohort study evaluating attributab
mortality and hospital stay. $A m \mathcal{F}$ Med 1993;94:281-8.

17 Pingleton SK. Complication of acute respiratory failure. $\mathrm{Am}$ Rev Respir Dis 1988;137:1463-93.

18 Stauffer JL, Olson DE, Petty TL. Complications and consequences of endotracheal intubation and tracheostomy. A
prospective study of 150 critically ill adult patients. Am $\mathcal{F}$ prospective study of 150 critically ill adult patients. Am $\mathcal{F}$ Med 1981;70:65-76.

19 Leeson-Payne CG, Aitkenhead AR. A prospective study to assess the demand for a high dependency unit. Anaesthesia 1995;50:383-7.

20 Dasgupta A, Rice R, Macha E, et al. Four-year experience with a unit for long-term ventilation (respiratory special care unit) at the Cleveland Clinic Foundation. Chest 1999; 116:447-55.

21 Scheinhorn DJ, Artinian BM, Catlin JL. Weaning from prolonged mechanical ventilation: the experience of a prolonged mechanical ventilation: the experi.

22 Latriano B, McCauley P, Astiz ME, et al. Non-ICU care of hemodynamically stable mechanically ventilated patients. hemst 1996;109:1591-6.

23 Gracey DR, Hardy D, Naessens JM, et al. The Mayo ventilator-dependent rehabilitation unit: a 5-year experience. Mayo Clin Proc 1997;72:13-9.
24 Brochard L, Mancebo J, Wysocki M, et al. Noninvasive ventilation for acute exacerbation of chronic obstructive pulmonary disease. $N$ Engl F Med 1995;333:817-22.

25 Connors AF, Dawson NV, Thomas C, et al. Outcomes following acute exacerbation of severe cronic obstructive lung disease. Am 7 Respir Crit Care Med 1996;154:959-67.

26 Hill AT, Hopkinson RB, Stableforth DE. Ventilation in a Birmigham intensive care unit 1993-1995: outcome for patients with chronic obstructive pulmonary disease. Respir Med 1998;92:156-61.

27 Plant PK, Owen JL, Elliott MW. Early use of non-invasive ventilation for acute exacerbations of chronic obstructive pulmonary disease on a general respiratory ward: a multicentre randomised trial. Lancet 2000;355:1931-5.

28 Sun X, Hakim RB, Knaus WA, et al. Prognosis of acute respiratory failure in patients with chronic obstructive pulmonary disease. In: Derenne JP, Whitelaw WA, Similowski T, eds. Acute respiratory failure in chronic obstructive pulmonary disease. New York: Marcel Dekker, 1996: 559-77.

29 Portier F, Defouilloy C, Muir JF. Determinants of immediate survival among chronic respiratory insufficiency patients admitted to an intensive care unit for acute respiratory failure. Chest 1992;101:204-10.

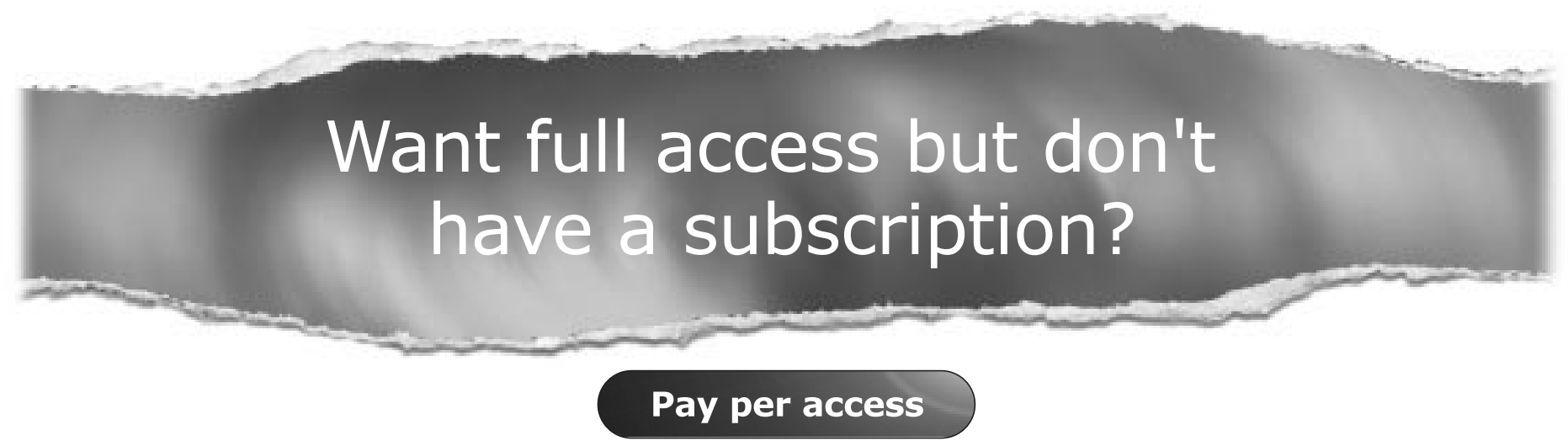

For just US $\$ 25$ you can have instant access to the whole website for 30 days. During this time you will be able to access the full text for all issues (including supplements) available. You will also be able to download and print any relevant pdf files for personal use, and take advantage of all the special features Thorax online has to offer.

www.thoraxjnl.com 